\title{
CXCL14 as an emerging immune and inflammatory modulator
}

\author{
Jing Lu, Mita Chatterjee, Hannes Schmid, Sandra Beck and Meinrad Gawaz
}

\begin{abstract}
CXCL14, a relatively novel chemokine, is a non-ELR (glutamic acid-leucine-arginine) chemokine with a broad spectrum of biological activities. CXCL14 mainly contributes to the regulation of immune cell migration, also executes antimicrobial immunity. The identity of the receptor for CXCL14 still remains obscure and therefore the intracellular signaling pathway is not entirely delineated. The present review summarizes the contribution of CXCL14 in these two aspects and discusses the biological mechanisms regulating CXCL14 expression and potential CXCL14 mediated functional implications in a variety of cells.
\end{abstract}

Keywords: CXCL14, Migration, Antimicrobial activity, Infection, Inflammation

\section{Background}

Chemokines are 8-14 $\mathrm{kDa}$ chemoattractant cytokines mainly regulating cell migration that play an important role in immune surveillance, inflammation, and cancer [1-3]. Chemokines induce intracellular signaling through $G$ protein-coupled cell-surface receptors [3]. They contain several (usually four) conserved cysteine residues. Based on the arrangement of these cysteine residues, two major chemokine groups have been categorised- the CC family with the first two cysteines adjacent to each other, and the CXC family that has one amino acid residue between the two cysteines. The chemokine (C-X-C Motif) ligand 14 gene (also known as

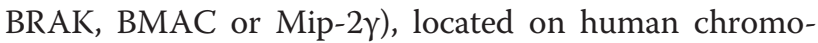
some $5 \mathrm{q} 31$, is expressed as a 99 amino acid residue precursor protein, which is processed to a 77 amino acid mature protein with a molecular weight of $9.4 \mathrm{kDa}$ having a highly basic isoelectric point of 9.9 (Fig. 1). CXCL14 was initially identified from breast and kidney cells in 1999 and is shown to be constitutively and widely expressed in normal tissue, especially in the epithelia $[4,5]$. On the other hand, significant downregulation or complete loss of expression is observed in many human cancer specimens and cancerous cell lines [5-8]. The primary amino acid sequence of CXCL14 is highly conserved in vertebrates [9]. Human and mouse

\footnotetext{
* Correspondence: meinrad.gawaz@med.uni-tuebingen.de Medizinische Klinik III, Kardiologie und Kreislauferkrankungen, Universität Tübingen, Otfried-Müller-Strasse 10, 72076 Tübingen, Germany
}

CXCL14 differ in only two amino acid residues. As a non-ELR (Glu-Leu-Arg) CXC chemokine, CXCL14 has a short $\mathrm{NH}_{2}$-terminal end with only two amino acids (SerLys) prior to the first typical Cysteine residue, while other CXC chemokines such as CXCL11 and CXCL12 have five or more residues in their $\mathrm{NH}_{2}$-terminal region (Fig. 1), which are essential for interaction with their cognate receptors $[10,11]$. Another unique characteristic of CXCL14 worth mentioning is that it has a five consecutive amino acid insertion $\left({ }^{41}\right.$ VSRYR $\left.^{45}\right)$ not seen in other CXC chemokines, which was reported to be essential for its degradation in cancer cells [12]. These characteristics separate CXCL14 from other CXC chemokines, which could be critical determinants governing its functions.

\section{Cellular sources of CXCL14}

CXCL14 is expressed by a variety of immune and nonimmune cells (Fig. 2) either constitutively or following distinct stimulatory influence. Freshly isolated resting human peripheral blood mononuclear cells do not exhibit CXCL14 expression at transcript (mRNA) level [6]. However following stimulation with lipopolysaccharide (LPS), CXCL14 mRNA is detected in monocytes and B cells, but not $\mathrm{T}$ cells [6]. The CXCL14 mRNA is also detected in THP-1 cell line and monocyte-derived dendritic cells (DCs), but not Jurkat cells [8]. Monocyte-derived immature dendritic cells (iDCs) secrete CXCL14 at low concentrations under basal conditions, which could be remarkably up-regulated by activin A [13]. Those leukocytes 


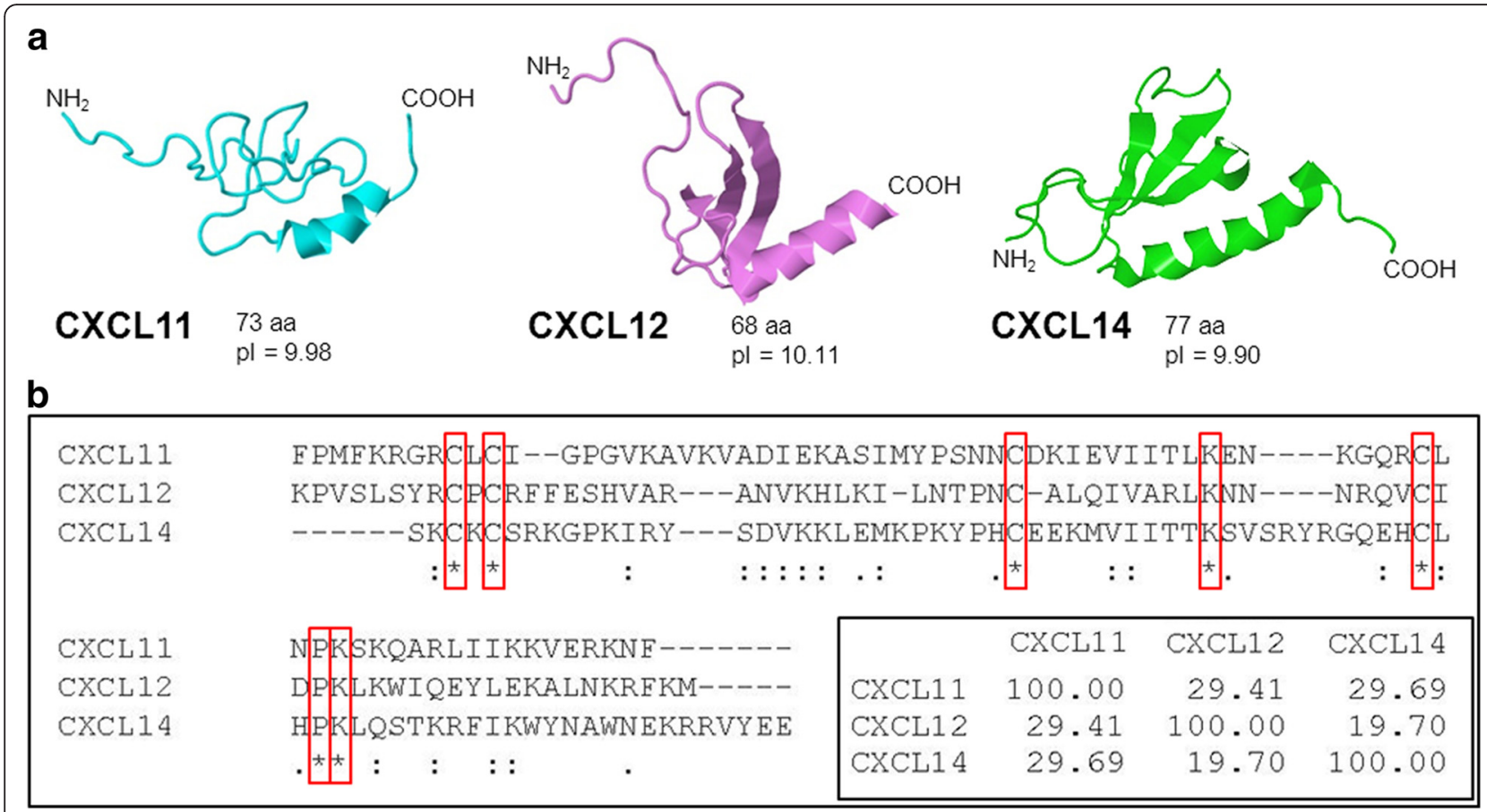

Fig. 1 Structural similarities of CXCL11, CXCL12 and CXCL14. a CXCL11, CXCL12 and CXCL14 are all small chemokines with a similar molecular structure. The three chemokines all share a C-terminal a-helix and comprise high pl values. Structures of the molecules were obtained by RCSB protein data bank and pdb-files were displayed with Jmol: an open-source Java viewer for chemical structures in 3D. http://www.jmol.org/. b CXCL11, CXCL12 and CXCL14 share high amino acid sequence conservation with 4 cysteines, 2 lysines and 1 proline residue being conserved throughout all 3 chemokines (conserved amino acids shown by asterisk*). Alignment was performed using Clustal Omega multiple sequence alignment tool. (References: [12,65-67])

expressing CXCL14 all can be chemoattracted by CXCL14 indicating an immune surveillance role for CXCL14 $[7,8]$. It is known that CXCL14 protein is highly expressed in healthy human epidermis and scattered cells of the dermis, while markedly less expression levels are observed in psoriatic and atopic dermatitis lesions [14]. Subsequently, it has been demonstrated that normal skin keratinocytes, dermal fibroblasts, dermal endothelial cells, and lamina propria cells but not epithelial cells in normal intestinal tissues are all sources of CXCL14, but not the immortal cell lines $[15,16]$. The cutaneous CXCL14 is involved in the recruitment of $\mathrm{CD} 14^{+} \mathrm{DC}$ precursors and influences their differentiation to Langerhans cells [16]. Those CXCL14-producing fibroblasts are co-localized with macrophages, which suggests a role for CXCL14 in macrophage development [15]. Another study showed CXCL14, as a much highly expressed gene in taste buds of tongue from human, and it could be secreted into the saliva suggesting an immune surveillance function for this protein in line with the presence of leukocytes in human saliva $[17,18]$. In addition, CXCL14 present on blood vessels in dermal plexus may be associated with its antiangiogenic effect in cancers $[16,19]$. Therefore the chief cellular sources of CXCL14 as present in circulating blood cells, the skin barrier and saliva suggest its potential involvement in first line of innate and later acquired immune defence against pathogenic intrusions.

\section{Regulation of CXCL14 expression at transcript and protein levels}

So far, the molecular mechanisms governing the expression of CXCL14 and CXCL14 mediated functions are not clear. It has been shown that CXCL14 expression could be inhibited by inflammatory stimuli such as TNF- $\alpha$ and LPS in epithelial tissues [4, 14]. Cigarette smoke condensate also could significantly suppress CXCL14 expression in normal human bronchial epithelial cells derived from healthy and non-smoking young male [20]. CXCL14 is significantly upregulated in inflamed joints of collageninduced arthritis and its overexpression exacerbates arthritis in a mouse model, which is in line with the studies carried out in patients with rheumatoid arthritis [21, 22]. In another study, Padilla et al., revealed that CXCL14 mRNA is markedly upregulated in the left anterior descending coronary artery (LAD) and descending thoracic aorta of obese pig as a result of the high-fat diet feeding, which suggests a possible role of CXCL14 in the progress of atherosclerosis [23]. In cultured porcine endothelial cells, this upregulation is not LPS or NF-kB dependent [23]. Not only could the expression of CXCL14 transcript 


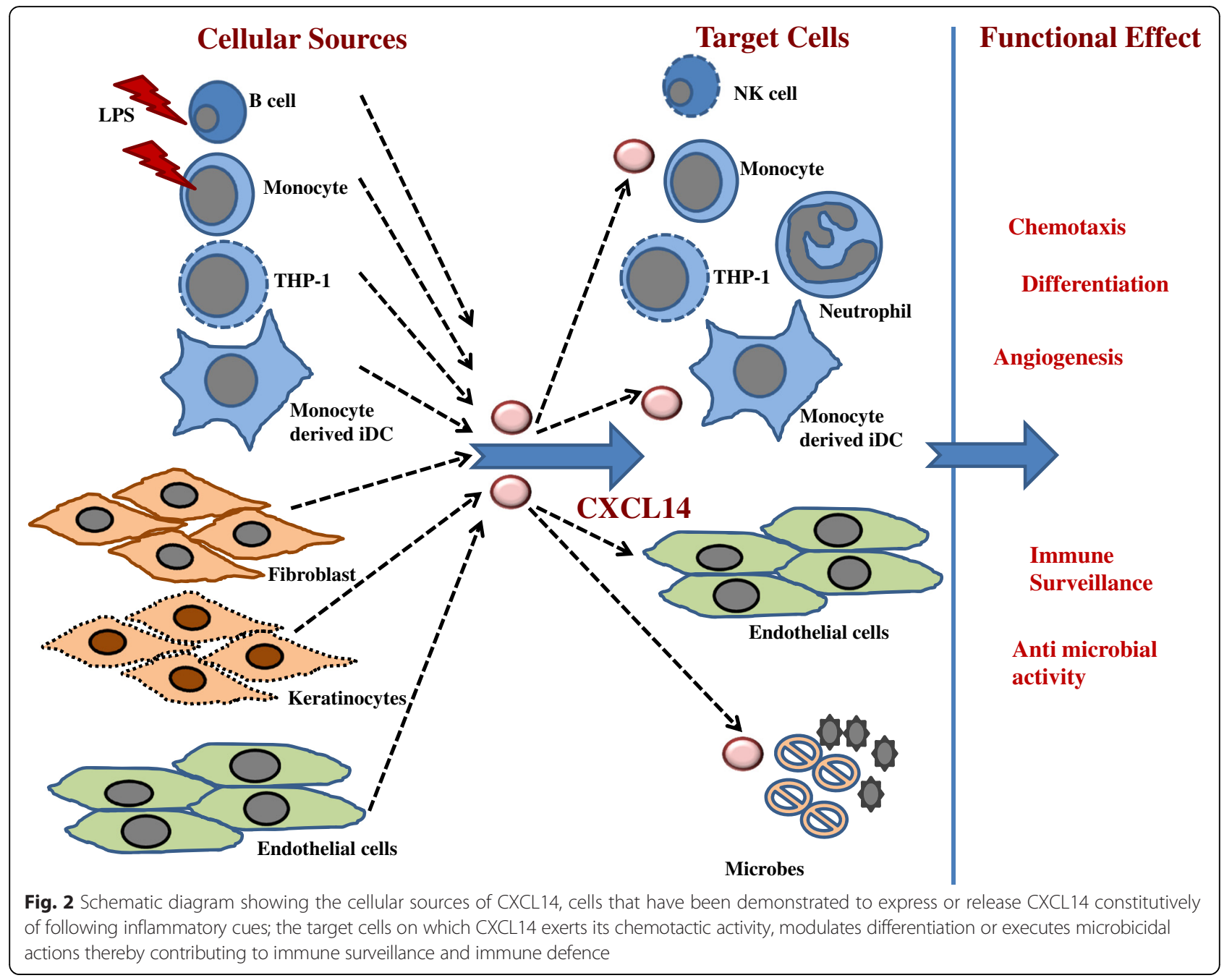

but CXCL14 also undergo post-transcriptional and posttranslational regulations. For example as an anti-microbial peptide (AMP), CXCL14 is completely degraded by the cysteine proteinase $\mathrm{SpeB}$ from a strictly human pathogen Streptococcus pyogenes [24].

Since a lot of research over years has been done to study CXCL14 mediated effects in cancer, its expressional regulation has been explored in several types of carcinomas. RhoBTB2, an atypical member of the Rho family, as a tumour suppressor which is downregulated in a large proportion of breast and lung cancers [25], is able to positively regulate CXCL14 expression in normal and cancerous epithelial cells [26]. In breast cancer cells, reactive oxygen species (ROS) caused by interrupted mitochondrial respiratory chain increases CXCL14 expression through activation of the activator protein-1 (AP-1) [27]. As a consequence CXCL14 promotes cancer cell motility through elevated cytosolic $\mathrm{Ca}^{2+}$ released from the endoplasmic reticulum (ER) mediated through interaction between CXCL14 and inositol 1,4,5-trisphosphate receptor on the ER [27]. Ultraviolet irradiation or serum deprivation of oral squamous cell carcinoma cells increases CXCL14 expression by stimulating the phosphorylation of the mitogen-activated protein kinase (MAPK) p38, which reduces cell viability [28]. In this study, the suppression of ERK phosphorylation was also seen, in line with the previous report of MEK-ERK induced downregulation of CXCL14 by activation of epidermal growth factor receptor (EGFR) in oral carcinoma cells $[29,30]$. It is also known that the phosphorylation of p38MAPK leads to activation of AP-1 [31], which was shown to be essential for elevation of CXCL14 expression as stimulated by ROS in breast cancer cells. These data suggest p38MAPK may play an important role through which different stress signal pathways regulate CXCL14 expression.

Due to its ill-defined receptor, intracellular signaling cascade initiated by CXCL14 still remains largely illusive. However it is known that CXCL14 can regulate calcium influx, NF- $\mathrm{KB}$ activity, activation of AP-1, and NOS1 as its intracellular molecular targets. Of interest, a post- 
translational mechanism for the loss of CXCL14 protein is reported in cancer and immortalized cell lines, but not in normal epithelial cells, which is regulated through ubiquitin-mediated, the $26 \mathrm{~S}$ proteasome participated degradation [12]. In human lung cancer cell line NCIH460, which does not express potential target GPCRs for CXCL14, CXCL14 stimulates NF- $\mathrm{kB}$ activity to promote its proliferation and migration by binding to some glycoproteins on cell surface [32]. In gastric adenocarcinoma tissues, the unusually high methylation in CXCL14 promoter region contributes to the low expression levels of CXCL14 resulting in poor prognosis [33]. In prostate and breast cancer, it is reported that the tumor-supportive effect of fibroblast-derived CXCL14 depends on nitric oxide synthase NOS1 mediated signaling mechanisms $[34,35]$. CXCL14 also facilitates invasiveness of pancreatic cancer cells by increasing nuclear NF-kB p65 levels [36]. In head and neck squamous cell carcinoma (HNSCC), CXCL14 expression and secretion and its anti-tumor effect is negatively regulated by RhoA/ROCK pathway. Therefore Fasudil, ROCK-specific inhibitor can stimulate CXCL14 expression [37]. In clear cell renal cell carcinoma, S100A6 (Calcyclin), as an oncogenic protein, negatively regulates CXCL14 expression, and knockdown of S100A6 promotes CXCL14mediated apoptosis and promotes tumour progression [38]. In osteosarcoma, activation of Iroquois homeobox 1 (IRX1), as a prometastatic protein, directly increases CXCL14 expression, and promotes osteosarcoma metastatic activity via elevated CXCL14/NF-kB signaling [39]. These experimental evidences from cancer research could facilitate to build a research base for endeavours in infection and inflammation or immunological research to decipher the potential mechanisms by which expression and stability of CXCL14 could be modulated.

\section{Role of CXCL14 in mediating leukocyte migration and differentiation}

As mentioned before, ambiguities still surround the identity of the cognate receptor for CXCL14. This makes it difficult to investigate the downstream intracellular signaling cascade of this chemokine completely. Recently, it has been demonstrated that CXCL14 specifically binds to CXCR4 with high affinity and supresses CXCL12-induced migration of THP-1 and human CD34 ${ }^{+}$bone marrow cells [40-42]. Another report indicates that CXCL14 in the conditioned medium from CD31 ${ }^{-}$ side population (SP) cells promotes cell migration through CXCR4 on the migrated cells of the regenerated pulp tissue in an ectopic tooth transplantation model. Interestingly, CD31- ${ }^{-}$PP cells express CXCL12 only to a minimum extent $[43,44]$. Thus conflicting experimental observations from different working groups have led to discrepancies regarding the chemotactic potential of
CXCL14, which are summarized in Table 1. Unlike some other non-ELR CXC chemokines that are chemotactic for activated T cells $[45,46]$, CXCL14 fails to promote chemotaxis of naive or activated $\mathrm{T}$ cells [7, 8, 15]. Among other cells which have been indicated to display chemotaxis towards CXCL14 are CESS (human B-cell line), THP-1 (human monocyte leukemia cell line), human neutrophils, human and murine immature dendritic cells, human monocytes (especially prostaglandin $E_{2}$ $\left(\mathrm{PGE}_{2}\right)$ or forsklin-treated monocytes), activated human natural killer cells (NKs), and human uterine NKs [7, 8, $15,45,47]$. Discrepancies might have risen due to difference in the methods of leukocyte isolation and use of CXCL14 protein from different sources by researchers, which include synthesised protein, murine CXCL14, CXCL14 present in conditioned media from transfected mammalian cell, and commercially available recombinant proteins from different sources $[6-8,16]$. Since the availability of recombinant human CXCL14 (rCXCL14), it has been demonstrated that CXCL14 effectively promotes chemotaxis of only immature, but not mature DCs both in vivo and in vitro $[19,48]$. In tumour tissues, the loss of CXCL14 is associated with reduced infiltration of DCs, which could otherwise elicit a specific antitumor immunity [48]. CXCL14 can further promote DC activation accompanied by up-regulation of NF- $\mathrm{kB}$ activity [48]. Moreover, Schaerli et al.,. demonstrated a role of CXCL14 and the epidermal environment in selectively recruiting blood $\mathrm{CD}_{14}{ }^{+} \mathrm{DC}$ precursors to be differentiated into epidermal Langerhans cells under steady-state condition by using a human epidermal tissue model, which is consistent with the constitutive expression of CXCL14 in the epidermis of healthy skin $[15,16]$. However, a series of synthetic CXCL14 variants with aminoterminal extensions show no chemoattractant effect on CD14 $4^{\text {high }}$ monocytes [16]. Presumably, the amino terminus of CXCL14 might be important for its interaction with the chemotactic receptor on target cells which respond to CXCL14. However, no significant difference is observed in the numbers of monocytes, macrophages and DCs in blood, bone marrow, and secondary lymphoid organs among CXCL14 knockout mice and their wild type counterparts, or among the CXCL14-transgenic (Tg) mice [22, 49]. Interestingly, enhanced $\mathrm{T}$ cell activation and proliferation was shown in CXCL14-Tg mice compared to the control mice, despite no alteration in the number of lymphocytes [22]. Very recently, significantly reduced number of uterine NK cells was demonstrated in $\mathrm{CXCL} 14^{-/-}$pregnant uterus as compared to $\mathrm{CXCL} 14^{+/-}$pregnant uterus, which is in line with the chemoattractive effect of CXCL14 on human uterine NK cells as observed in vitro $[45,50]$. These observations indicate that CXCL14 is not indispensable for maintaining chemotaxis or steady state kinetics and 
Table 1 Cellular sources, target cells and potential functional significance of CXCL14 to immune functions

\begin{tabular}{|c|c|c|c|c|}
\hline $\begin{array}{l}\text { Cells or tissues expressing CXCL14 } \\
\text { as mRNA or protein }\end{array}$ & Target cells for CXCL14 & Functional effects of CXCL14 & $\begin{array}{l}\text { Sources of recombinant } \\
\text { CXCL14 protein }\end{array}$ & Reference \\
\hline $\begin{array}{l}\text { mRNA detected in human heart, } \\
\text { brain, placenta, lung, liver, skeletal } \\
\text { muscle, kidney, and pancreas; colon } \\
\text { adenocarcinoma cell SW 485, and } \\
\text { melanoma cell MDA-MB-435 }\end{array}$ & & $\begin{array}{l}\text { No in vitro effect on human } \\
\text { endothelial cell proliferation or } \\
\text { tubule formation; No chemotactic } \\
\text { effects on human or murine T cells, } \\
\text { B cells, monocytes, NK cells, or } \\
\text { granulocytes }\end{array}$ & Synthesized human CXCL14 & $\begin{array}{l}1999 \text { Hromas } \\
\text { et al. [5] }\end{array}$ \\
\hline
\end{tabular}

mRNA detected in mouse brain, ovary, lung, and muscle; Human intestine, colon, kidney, liver, spleen, thymus, placenta, brain, pancreas, B cells, macrophages, CESS (human B cell line), A20 (murine B cell line), THP-1 (human monocyte skeletal muscle, heart, cervix, uterus, leukemia cell) and breast

mRNA detected in human kidney, intestine, brain, placenta, skeletal muscle, liver, spleen, thymus, and pancreas; very faint expression in testis, ovary, heart, and lung.

Epithelium of tubules of mouse kidney; hepatocytes in mouse liver; monocyte-derived dendritic cell (DC); THP-1

mRNA in human skin, kidney, intestine, spleen, colon, muscle, liver, brain, placenta, thymus, breast, exocervix, ovary and heart; squamous epithelium; oral epithelial cells, epidermal keratinocytes; LPS activated B cells and monocytes; inflammatory and stromal cells adjacent to carcinomas

mRNA in human epithelial layer of intestine, kidney, stomach, colon, appendix, trachea; Skin keratinocytes, dermal fibroblasts, lamina propria cells in intestine; HaCaT (human keratinocyte cell line)

CXCL14 protein expression in human: Suprabasal layers of tongue mucosa, stromal cells adjacent to tumors

CXCL14 protein in human: Oral squamous epithelium

Protein expression in human: blood vessels in dermal plexus and epidermal keratinocytes of skin

DCs stimulated with activin A

Protein in human: glandular epithelial cells in endometrium in the secretory phase of menstrual cycle
Human neutrophils and monocyte-derived DC

A strong chemoattractant for human neutrophils, and weaker for human DC

Human CXCL14 in

supernatant from transfected 293 cells
2000 Cao et al. [8]
Potential role in host-tumor interactions
2000 Frederick et al. [6]
Freshly isolated monocytes Monocyte chemoattractant; (weak), monocytes treated with prostaglandin $\mathrm{E}_{2}$ $\left(\mathrm{PGE}_{2}\right)$ or forskolin (strong)

human endothelial cells, monocyte-derived immature dendritic cells (iDCs)

Human monocyte-derived iDCs

\section{CD $14^{+}$DC precursors} derived from $\mathrm{CD}_{3} 4^{+}$ hematopoietic progenitor cells (HPCs) and blood $\mathrm{CD} 14^{+}$monocytes

Activated human natural killer(NK) cells; an IL-2dependent natural killer leukemia cell line; monocyte-derived iDCs

Human and murine iDCs

Human uterine natural killer (uNK) cells potential role in macrophage
development; CXCL14 signals through Bordetella pertussis toxinsensitive receptor in $\mathrm{PGE}_{2}$-treated monocytes

Potent inhibitor of chemotaxis for human endothelial cells and in vivo angiogenesis

Stimulation of iDCs migration and maturation, and NF-KB activation

Stimulation of $\mathrm{CD}_{14}{ }^{+}$monocyte migration, possible contribution to the differentiation of $\mathrm{CD} 14^{+} \mathrm{DC}$ precursors into Langerhans cell-like cells in epidermal tissue under steady-state condition

Stimulation of activated human NK cells and iDCs; no effect on proliferation or cytotoxic activity of normal human NK cells

Mediator for activin A-induced migration of iDCs

Stimulation of UNK cell migration during the secretory phase of the cycle
Synthesized human CXCL14 2001 Kurth et al. [15]

Recombinant human

CXCL14

2004

Shellenberger et al. [19]

Recombinant human CXCL14

Recombinant human CXCL14 and CXCL14 purified from supernatant of primary keratinocyte culture

CXCL14 synthetic peptide, CXCL14 expressed in bacterial vector and HPLCpurified; recombinant eukaryotic CXCL14

Recombinant human CXCL14

Recombinant human CXCL14
2005 Shurin et al. [48]

2005 Schaerli et al. [16]

2006 Starnes et al. [47]

2009 Salogni et al. [13]

2010 Mokhtar et al. [45] 
Table 1 Cellular sources, target cells and potential functional significance of CXCL14 to immune functions (Continued)

\begin{tabular}{|c|c|c|c|}
\hline $\begin{array}{l}\text { Human THP-1 cells and } \\
\text { iDCs }\end{array}$ & $\begin{array}{l}\text { The chemotactic effect on THP-1 } \\
\text { and iDCs }\end{array}$ & $\begin{array}{l}\text { Recombinant human } \\
\text { CXCL14 }\end{array}$ & $\begin{array}{l}2010 \\
\text { Tanegashima } \\
\text { et al. [64] }\end{array}$ \\
\hline $\begin{array}{l}\text { PGE }_{2} \text {-treated THP-1, } \\
\text { Pseudomonas aeruginosa, } \\
\text { Streptococcus mitis, and } \\
\text { Streptococcus pneumoniae }\end{array}$ & $\begin{array}{l}\text { Induction of THP-1 migration; } \\
\text { antimicrobial activity to facilitate } \\
\text { bacterial clearance in mouse lung }\end{array}$ & $\begin{array}{l}\text { Recombinant human } \\
\text { CXCL14 }\end{array}$ & $\begin{array}{l}2015 \text { Dai et al. } \\
\text { [62] }\end{array}$ \\
\hline
\end{tabular}

turnover of immune cells in vivo and might have other chemokines complementing its functions. Among all 48 human chemokines, only CXCL12 (also known as SDF- $1 \alpha$ ) matches the high degree of CXCL14 conservation in vertebrate species [51]. Both are known as evolutionary ancient chemokines due to their highly conservative sequence throughout different vertebrate classes and their homeostatic roles, which suggests that CXCL14, evolved with CXCL12, might have the potential to regulate the function of the CXCL12-CXCR4 signaling axis or play a compensatory role when CXCL12 is absent $[9,40,43,52,53]$. However, other report demonstrates that CXCR4 alone is not sufficient to initiate CXCL14-mediated chemotactic response. CXCL14 also fails to influence the CXCL12CXCR4 mediated signaling axis in Jurkat cells and HEK293 cells transfected with CXCR4 [54]. So other potential GPCR or signaling mediators still need to be identified for CXCL14-specific biological activities in co-operation with CXCR4.

\section{Antimicrobial activity of CXCL14}

Although human skin is constantly exposed to a variety of microorganisms, normally no signs of infection or excessive microbial growth are shown on our healthy body surfaces [55]. Apart from the physical barrier, the existence of abundant antimicrobial peptides (AMPs) contributes to prevent a wide spectrum of bacteria, yeast, and some enveloped viruses from infiltrating into the live part of the epidermis [56-59]. Defensins and cathelicidin LL-37 are the main AMPs expressed in human skin $[58,59]$. Interestingly, CXCL14 shares striking common structural characteristics with them, including large, positively charged patches on its molecular surface, three anti-parallel $\beta$-strands shown in $\beta$-defensin, and a $\mathrm{C}$-terminal $\alpha$-helix that is typical for cathelicidin LL-37 (Fig. 1) [60]. CXCL14 and human $\beta$-defensin both show bactericidal activity against Gram-positive coccoid Finegoldia magna residing in skin epidermis and the virulent pathogen Streptococcus pyogenes at similar concentrations [4]. Thus, in addition to its chemoattractant effects on immune and inflammatory cells, recombinant CXCL14 demonstrates direct antimicrobial effects against Escherichia coli and Staphylococcus aureus, but not Candida albicans at $10 \mu \mathrm{g} / \mathrm{ml}$ [61]. Characteristic topological formation of a large positive electrostatic patch on the molecular surface of CXCL14 is required for its antimicrobial activity as deciphered in comparison of antimicrobial chemokines with non-antimicrobial chemokines. Subsequently, CXCL14 has demonstrated to have a broad range of antimicrobial effects against cutaneous Gram-positive bacteria and Candida albicans as well as the Gram-negative enterobacterium Escherichia coli, which could not be counteracted by increased salt concentrations and skin-typical pH conditions [14]. Those antimicrobial activities exhibited by both human and murine CXCL14 could be neutralized by antiCXCL14 mAb [14]. Since CXCL14 is constantly produced in the epidermis and dermis of healthy human skin and other epithelial tissues but is markedly decreased in the presence of inflammation and disease, it has been proposed that CXCL14 plays a unique role in antimicrobial immunity prior to the establishment of inflammation [4, 14, 15].

Moreover, CXCL14 also plays prominent anti-microbial role in animal models of respiratory tract infection. It executes bactericidal actions against Pseudomonas aeruginosa, Streptococcus mitis, and Streptococcus pneumoniae partially via bacterial membrane depolarization, damage and via its binding affinity for bacterial DNA [62]. In this study, the authors showed that the disulphide bonds and the C-terminal $\alpha$-helix of CXCL14 do not seem to be responsible for its antimicrobial activity [62], although a high proportion of cationic amino acids in the $\alpha$-helix part might be involved in the disruption of bacterial membranes by binding with negatively charged molecules in bacterial membranes. The N-terminal region of CXCL14 is critical for its antimicrobial activity, at least, against Gram-negative bacteria such as E. coli and Pseudomonas aeruginosa, while the CXCL14 fragment showed no chemoattractant effect for human blood monocytes at micromolar concentrations [62]. To substantiate the antibacterial effects of CXCL14 both CXCL14 mRNA and protein expression levels are shown to be increased following Pseudomonas aeruginosa infection in the lung tissue of wild type mice. On the other hand, CXCL14-deficient mice exhibit reduced bacterial clearance in the lungs infected with Streptococcus pneumoniae but not Pseudomonas aeruginosa [62]. This is the first in vivo demonstration that CXCL14 has a role in host defence against lung infections 
induced by Gram-positive bacteria. The exact antimicrobial mechanism for CXCL14 remains to be deciphered. Nevertheless, it might be considered that classical AMPs like defensins and cathelicidin exert less influence on Gram-positive bacteria compared with Gram-negative bacteria. For instance, cathelicidin deficient mice showed an impaired lung bacterial clearance in response to Gram-negative Pseudomonas aeruginosa [63]. These studies suggest the possibility that different structural properties of CXCL14 and antimicrobial mode of action might be associated with extermination of Gram-negative and Gram-positive bacterial species. The molecular regions of CXCL14 acting as an AMP and a chemoattractant appears to be different, and CXCL14 shows a non-redundant role as an AMP in lung infections. Future studies utilizing animal models of systemic infection like sepsis could reveal the antimicrobial potential of CXCL14 not only as a therapeutic alternative administered to these models but decipher the role of active immune cell derived CXCL14 in providing antimicrobial defence under physiological conditions.

\section{Conclusions}

During recent years of endeavours in the ever expanding field of chemokine research CXCL14 has emerged as a potential mediator of inflammatory processes and immune response as highlighted in this review. It also bears the potential to influence other chemokine functions particularly that of CXCL12. Identification of its cognate receptor in the coming years would help reveal the molecular mechanisms by which CXCL14 might influence immune response also uncover more cellular targets under diverse pathophysiological conditions which involve immune cells.

\section{Competing interest}

The authors declare that they have no competing interests.

\section{Acknowledgement}

The ongoing CXCL14 project is supported by the Deutsche

Forschungsgemeinschaft (Klinische Forschungsgruppe-KFO-274: "Platelets-

Molecular Mechanisms and Translational Implications").

Received: 19 September 2015 Accepted: 23 December 2015

Published online: 05 January 2016

\section{References}

1. Zlotnik A, Yoshie O. Chemokines: a new classification system and their role in immunity. Immunity. 2000;12:121-7.

2. Moser B, Wolf M, Walz A, Loetscher P. Chemokines: multiple levels of leukocyte migration control. Trends Immunol. 2004;25:75-84.

3. Zlotnik A, Yoshie O, Nomiyama H. The chemokine and chemokine receptor superfamilies and their molecular evolution. Genome Biol. 2006;7:243.

4. Frick IM, Nordin SL, Baumgarten M, Morgelin M, Sorensen OE, Olin Al, et al. Constitutive and inflammation-dependent antimicrobial peptides produced by epithelium are differentially processed and inactivated by the commensal Finegoldia magna and the pathogen Streptococcus pyogenes. J Immunol. 2011;187:4300-9.
5. Hromas R, Broxmeyer HE, Kim C, Nakshatri H, Christopherson KN, Azam M, et al. Cloning of BRAK, a novel divergent CXC chemokine preferentially expressed in normal versus malignant cells. Biochem Biophys Res Commun. 1999;255:703-6.

6. Frederick MJ, Henderson $Y, X u X$, Deavers MT, Sahin AA, Wu H, et al. In vivo expression of the novel CXC chemokine BRAK in normal and cancerous human tissue. Am J Pathol. 2000;156:1937-50.

7. Sleeman MA, Fraser JK, Murison JG, Kelly SL, Prestidge RL, Palmer DJ, et al. B cell- and monocyte-activating chemokine (BMAC), a novel non-ELR alphachemokine. Int Immunol. 2000;12:677-89.

8. Cao X, Zhang W, Wan T, He L, Chen T, Yuan Z, et al. Molecular cloning and characterization of a novel CXC chemokine macrophage inflammatory protein-2 gamma chemoattractant for human neutrophils and dendritic cells. Vol. 2000;165:2588-95.

9. Huising MO, van der Meulen T, Flik G, Verburg-van KB. Three novel carp CXC chemokines are expressed early in ontogeny and at nonimmune sites. Eur J Biochem. 2004;271:4094-106.

10. Clark-Lewis I, Dewald B, Loetscher M, Moser B, Baggiolini M. Structural requirements for interleukin-8 function identified by design of analogs and CXC chemokine hybrids. J Biol Chem. 1994;269:16075-81.

11. Rajagopalan $L$, Rajarathnam K. Structural basis of chemokine receptor function-a model for binding affinity and ligand selectivity. Biosci Rep. 2006;26:325-39.

12. Peterson FC, Thorpe JA, Harder AG, Volkman BF, Schwarze SR. Structural determinants involved in the regulation of CXCL14/BRAK expression by the 26 S proteasome. J Mol Biol. 2006;363:813-22.

13. Salogni L, Musso T, Bosisio D, Mirolo M, Jala VR, Haribabu B, et al. Activin A induces dendritic cell migration through the polarized release of CXC chemokine ligands 12 and 14. Blood. 2009;113:5848-56.

14. Maerki C, Meuter S, Liebi M, Muhlemann K, Frederick MJ, Yawalkar N, et al. Potent and broad-spectrum antimicrobial activity of CXCL14 suggests an immediate role in skin infections. J Immunol. 2009;182:507-14.

15. Kurth I, Willimann K, Schaerli P, Hunziker T, Clark-Lewis I, Moser B. Monocyte selectivity and tissue localization suggests a role for breast and kidneyexpressed chemokine (BRAK) in macrophage development. J Exp Med. 2001;194:855-61.

16. Schaerli P, Willimann K, Ebert LM, Walz A, Moser B. Cutaneous CXCL14 targets blood precursors to epidermal niches for Langerhans cell differentiation. Immunity. 2005;23:331-42.

17. Hevezi P, Moyer BD, Lu M, Gao N, White E, Echeverri F, et al. Genome-wide analysis of gene expression in primate taste buds reveals links to diverse processes. PLoS One. 2009;4:e6395.

18. Dawes C, Pedersen AM, Villa A, Ekstrom J, Proctor GB, Vissink A, et al. The functions of human saliva: a review sponsored by the world workshop on oral medicine VI. Arch Oral Biol. 2015;60:863-74.

19. Shellenberger $T D$, Wang $M$, Gujrati M, Jayakumar $A$, Strieter RM, Burdick MD, et al. BRAK/CXCL14 is a potent inhibitor of angiogenesis and a chemotactic factor for immature dendritic cells. Cancer Res. 2004;64:8262-70.

20. Parsanejad R, Fields WR, Steichen TJ, Bombick BR, Doolittle DJ. Distinct regulatory profiles of interleukins and chemokines in response to cigarette smoke condensate in normal human bronchial epithelial (NHBE) cells. J Interferon Cytokine Res. 2008;28:703-12.

21. Lindberg J, Af KE, Catrina Al, Nilsson P, Klareskog L, Ulfgren AK, et al. Effect of infliximab on mRNA expression profiles in synovial tissue of rheumatoid arthritis patients. Arthritis Res Ther. 2006;8:R179.

22. Chen L, Guo L, Tian J, He H, Marinova E, Zhang P, et al. Overexpression of CXC chemokine ligand 14 exacerbates collagen-induced arthritis. J Immunol. 2010;184:4455-9.

23. Padilla J, Jenkins NT, Lee $\mathrm{S}$, Zhang $\mathrm{H}$, Cui J, Zuidema MY, et al. Vascular transcriptional alterations produced by juvenile obesity in Ossabaw swine. Physiol Genomics. 2013;45:434-46.

24. Egesten $\mathrm{A}$, Olin Al, Linge HM, Yadav M, Morgelin M, Karlsson A, et al. SpeB of Streptococcus pyogenes differentially modulates antibacterial and receptor activating properties of human chemokines. PLoS One. 2009;: 4 e4769.

25. Hamaguchi M, Meth $\mathrm{J}$, von Klitzing C, Wei W, Esposito D, Rodgers L, et al. $\mathrm{DBC2}$, a candidate for a tumor suppressor gene involved in breast cancer. Proc Natl Acad Sci U S A. 2002:99:13647-52.

26. McKinnon CM, Lygoe KA, Skelton L, Mitter R, Mellor H. The atypical Rho GTPase RhoBTB2 is required for expression of the chemokine CXCL14 in normal and cancerous epithelial cells. Oncogene. 2008;27:6856-65. 
27. Pelicano H, Lu W, Zhou Y, Zhang W, Chen Z, Hu Y, et al. Mitochondria dysfunction and reactive oxygen species imbalance promote breast cancer cell motility through a CXCL14-mediated mechanism. Cancer Res. 2009;69: 2375-83.

28. Ozawa S, Ito S, Kato Y, Kubota E, Hata R. Human p38 delta MAP kinase mediates UV irradiation induced up-regulation of the gene expression of chemokine BRAK/CXCL14. Biochem Biophys Res Commun. 2010;396:1060-4.

29. Ozawa S, Kato Y, Komori R, Maehata Y, Kubota E, Hata R. BRAK/CXCL14 expression suppresses tumor growth in vivo in human oral carcinoma cells. Biochem Biophys Res Commun. 2006;348:406-12.

30. Ito S, Ozawa S, Ikoma T, Yajima N, Kiyono T, Hata R. Expression of a chemokine BRAK/CXCL14 in oral floor carcinoma cells reduces the settlement rate of the cells and suppresses their proliferation in vivo. Biomed Res. 2010;31:199-206.

31. Efimova T, Broome AM, Eckert RL. A regulatory role for p38 delta MAPK in keratinocyte differentiation. Evidence for p38 delta-ERK1/2 complex formation. J Biol Chem. 2003;278:34277-85.

32. Park CR, You DJ, Kim DK, Moon MJ, Lee C, Oh SH, et al. CXCL14 enhances proliferation and migration of $\mathrm{NCl}-\mathrm{H} 460$ human lung cancer cells overexpressing the glycoproteins containing heparan sulfate or sialic acid. J Cell Biochem. 2013;114:1084-96.

33. Hu C, Lin F, Zhu G, Xue X, Ding Y, Zhao Z, et al. Abnormal hypermethylation of promoter region downregulates chemokine CXC ligand 14 expression in gastric cancer. Int J Oncol. 2013;43:1487-94.

34. Augsten M, Hagglof C, Olsson E, Stolz C, Tsagozis P, Levchenko T, et al. CXCL14 is an autocrine growth factor for fibroblasts and acts as a multi-modal stimulator of prostate tumor growth. Proc Natl Acad Sci U S A. 2009;106:3414-9.

35. Augsten M, Sjoberg E, Frings O, Vorrink SU, Frijhoff J, Olsson E, et al. Cancerassociated fibroblasts expressing CXCL14 rely upon NOS1-derived nitric oxide signaling for their tumor-supporting properties. Cancer Res. 2014;74: 2999-3010.

36. Wente MN, Mayer C, Gaida MM, Michalski CW, Giese T, Bergmann F, et al. CXCL14 expression and potential function in pancreatic cancer. Cancer Lett. 2008;259:209-17.

37. Miyamoto C, Maehata Y, Motohashi K, Ozawa S, Ikoma T, Hidaka K, et al. Fasudil, a Rho kinase inhibitor, suppresses tumor growth by inducing CXCL14/BRAK in head and neck squamous cell carcinoma. Biomed Res. 2014:35:381-8

38. Lyu XJ, Li HZ, Ma X, Li XT, Gao Y, Ni D, et al. Elevated S100A6 (Calcyclin) enhances tumorigenesis and suppresses CXCL14-induced apoptosis in clear cell renal cell carcinoma. Oncotarget. 2015;6:6656-69.

39. Lu J, Song G, Tang Q, Zou C, Han F, Zhao Z, et al. IRX1 hypomethylation promotes osteosarcoma metastasis via induction of CXCL14/NF-kappaB signaling. J Clin Invest. 2015;125:1839-56.

40. Tanegashima K, Suzuki K, Nakayama Y, Tsuji K, Shigenaga A, Otaka A, et al. CXCL14 is a natural inhibitor of the CXCL12-CXCR4 signaling axis. FEBS Lett. 2013;587:1731-5.

41. Tanegashima K, Tsuji K, Suzuki K, Shigenaga A, Otaka A, Hara T. Dimeric peptides of the C-terminal region of CXCL14 function as CXCL12 inhibitors. FEBS Lett. 2013;587:3770-5.

42. Tsuji K, Tanegashima K, Sato K, Sakamoto K, Shigenaga A, Inokuma T, et al. Efficient one-pot synthesis of CXCL14 and its derivative using an Nsulfanylethylanilide peptide as a peptide thioester equivalent and their biological evaluation. Bioorg Med Chem. 2015;23:5909-14.

43. Hayashi Y, Murakami M, Kawamura R, Ishizaka R, Fukuta O, Nakashima M. CXCL14 and MCP1 are potent trophic factors associated with cell migration and angiogenesis leading to higher regenerative potential of dental pulp side population cells. Stem Cell Res Ther. 2015;6:111.

44. Iohara $K$, Zheng L, Wake $H$, Ito $M$, Nabekura J, Wakita $H$, et al. A novel stem cell source for vasculogenesis in ischemia: subfraction of side population cells from dental pulp. Stem Cells. 2008;26:2408-18.

45. Mokhtar NM, Cheng CW, Cook E, Bielby H, Smith SK, Charnock-Jones DS Progestin regulates chemokine (C-X-C motif) ligand 14 transcript level in human endometrium. Mol Hum Reprod. 2010;16:170-7.

46. Bleul CC, Fuhlbrigge RC, Casasnovas JM, Aiuti A, Springer TA. A highly efficacious lymphocyte chemoattractant, stromal cell-derived factor 1 (SDF-1) J Exp Med. 1996;184:1101-9.

47. Starnes T, Rasila KK, Robertson MJ, Brahmi Z, Dahl R, Christopherson K, et al. The chemokine CXCL14 (BRAK) stimulates activated NK cell migration: implications for the downregulation of CXCL14 in malignancy. Exp Hematol. 2006;34:1101-5.
48. Shurin GV, Ferris RL, Tourkova IL, Perez L, Lokshin A, Balkir L, et al. Loss of new chemokine CXCL14 in tumor tissue is associated with low infiltration by dendritic cells (DC), while restoration of human CXCL14 expression in tumor cells causes attraction of DC both in vitro and in vivo. J Immunol. 2005;174:5490-8.

49. Meuter S, Schaerli P, Roos RS, Brandau O, Bosl MR, von Andrian UH, et al. Murine CXCL14 is dispensable for dendritic cell function and localization within peripheral tissues. Mol Cell Biol. 2007;27:983-92.

50. Cao Q, Chen H, Deng Z, Yue J, Chen Q, Cao Y, et al. Genetic deletion of Cxcl14 in mice alters uterine NK cells. Biochem Biophys Res Commun. 2013; 435:664-70.

51. DeVries ME, Kelvin AA, Xu L, Ran L, Robinson J, Kelvin DJ. Defining the origins and evolution of the chemokine/chemokine receptor system. J Immunol. 2006;176:401-15.

52. Huising MO, Stet RJ, Kruiswijk CP, Savelkoul HF, Lidy VKB. Molecular evolution of CXC chemokines: extant CXC chemokines originate from the CNS. Trends Immunol. 2003:24:307-13.

53. Garcia-Andres C, Torres M. Comparative expression pattern analysis of the highly conserved chemokines SDF1 and CXCL14 during amniote embryonic development. Dev Dyn. 2010;239:2769-77.

54. Otte M, Kliewer A, Schutz D, Reimann C, Schulz S, Stumm R. CXCL14 is no direct modulator of CXCR4. FEBS Lett. 2014:588:4769-75.

55. Schroder JM, Harder J. Antimicrobial skin peptides and proteins. Cell Mol Life Sci. 2006;63:469-86.

56. Braff MH, Bardan A, Nizet V, Gallo RL. Cutaneous defense mechanisms by antimicrobial peptides. J Invest Dermatol. 2005;125:9-13.

57. Brown KL, Hancock RE. Cationic host defense (antimicrobial) peptides. Curr Opin Immunol. 2006;18:24-30.

58. Ganz T. Defensins: antimicrobial peptides of innate immunity. Nat Rev Immunol. 2003;3:710-20.

59. Izadpanah A, Gallo RL. Antimicrobial peptides. J Am Acad Dermatol. 2005; 52:381-90. quiz 391-2.

60. Wolf M, Moser B. Antimicrobial activities of chemokines: not just a side-effect? Front Immunol. 2012;3:213.

61. Yang D, Chen Q, Hoover DM, Staley P, Tucker KD, Lubkowski J, et al. Many chemokines including CCL20/MIP-3alpha display antimicrobial activity. J Leukoc Biol. 2003:74:448-55.

62. Dai C, Basilico P, Cremona TP, Collins P, Moser B, Benarafa C, et al. CXCL14 displays antimicrobial activity against respiratory tract bacteria and contributes to clearance of Streptococcus pneumoniae pulmonary infection. J Immunol. 2015;194:5980-9.

63. Kovach MA, Ballinger MN, Newstead MW, Zeng X, Bhan U, Yu FS, et al. Cathelicidin-related antimicrobial peptide is required for effective lung mucosal immunity in Gram-negative bacterial pneumonia. J Immunol. 2012; 189:304-11

64. Tanegashima K, Suzuki K, Nakayama Y, Hara T. Antibody-assisted enhancement of biological activities of CXCL14 in human monocytic leukemia-derived THP-1 cells and high fat diet-induced obese mice. Exp Cell Res. 2010;316:1263-70

65. Booth V, Clark-Lewis I, Sykes BD. NMR structure of CXCR3 binding chemokine CXCL11 (ITAC). Protein Sci. 2004;13:2022-8.

66. Veldkamp CT, Ziarek JJ, Su J, Basnet H, Lennertz R, Weiner JJ, et al. Monomeric structure of the cardioprotective chemokine SDF-1/CXCL12. Protein Sci. 2009;18:1359-69.

67. Sievers F, Wilm A, Dineen D, Gibson TJ, Karplus K, Li W, et al. Fast, scalable generation of high-quality protein multiple sequence alignments using Clustal Omega. Molecular systems biology. 2011;7:539. PMID: 21988835. 